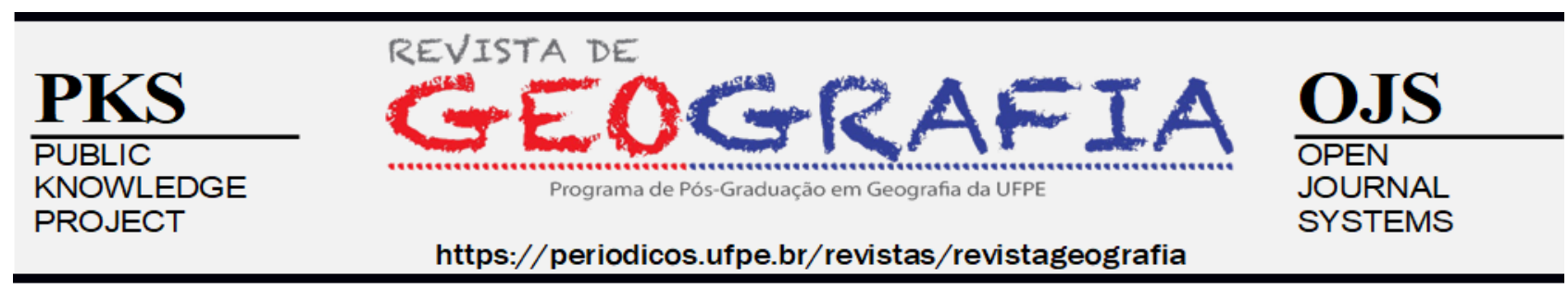

\title{
CAMPESINATO, AGRONEGÓCIO E TRABALHO NO BRASIL E NO MÉXICO
}

\author{
Angela dos Santos Machado ${ }^{1}$, Luciano Concheiro Borquez ${ }^{1}$
}

\begin{abstract}
${ }^{1}$ Universidade Estadual Paulista (UNESP), Faculdade de Ciências e Tecnologia (FCT), Campus de Presidente Prudente, E-mail: angelasm.geo@gmail.com,Orcid: http://orcid.org/0000-0001-9831-5307

${ }^{2}$ Universidad Autónoma Metropolitana (UAM), E-mail: concheir@gmail.com,OOrcid: http://orcid.org/0000-0002-85894052
\end{abstract}

Artigo recebido em 04/08/2021 e aceito em 18/09/2021

\section{RESUMO}

Os camponeses são impactados pela agricultura capitalista, pelas políticas neoliberais e pela forma como os países estão inseridos na divisão internacional do trabalho. Neste artigo, discutimos essas questões com o exemplo do Valle de San Quintín, localizado no estado de Baja California, no México, e do Pontal do Paranapanema, em São Paulo, Brasil. Nesses territórios de domínio do agronegócio, buscamos compreender como se entrelaçam a questão agrária, o trabalho e a determinação social do processo saúde-doença. A abordagem teórico-metodológica consistiu na revisão bibliográfica, no trabalho de campo e na produção de entrevistas com trabalhadoras e trabalhadores camponeses de ambos os países. Os resultados alcançados demonstram que por trás da imagem de modernidade das empresas do agronegócio, há trabalho precário e degradante, seja através da intensificação da jornada laboral, seja pelo uso de novas tecnologias, seja pela combinação de ambas. Mas, também há resistências e experiências que demonstram as disputas e relações de poder constituintes dos territórios.

Palavras-chave: Campesinato; Agronegócio; Trabalho; Brasil; México.

\section{PEASANTRY, AGRIBUSINESS AND LABOR IN BRAZIL AND MEXICO}

\begin{abstract}
Peasants are impacted by capitalist agriculture; neoliberal policies and the way countries are inserted in the international division of labor. In this article, we discuss these issues with the example of Valle de San Quintin, located in the state of Baja California, Mexico, and Pontal do Paranapanema, São Paulo, Brazil. In these agribusiness domains territories, we seek to understand how the agrarian issue, work and the social determination of the health-disease process intertwine. The theoretical-methodological approach consisted of literature review, field work and the production of interviews with peasant workers from both countries. The results achieved demonstrate that behind the image of modernity of agribusiness companies, there is precarious and degrading work, either through the intensification of the working hours, or through the use of new technologies, or through the combination of both. But there are also resistances and experiences that demonstrate the disputes and power relations that constitute the territories.
\end{abstract}

Keywords: Peasantry. Agribusiness. Labor. Brazil. Mexico. 


\title{
CAMPESINADO, AGRONEGÓCIO Y TRABAJO EN BRASIL Y MÉXICO
}

\begin{abstract}
RESUMEN
Los campesinos son impactados por la agricultura capitalista, las políticas neoliberales y la forma en que los países se insertan en la división internacional del trabajo. En este artículo discutimos estos temas con el ejemplo del Valle de San Quintín, ubicado en el estado de Baja California, México, y Pontal do Paranapanema, São Paulo, Brasil. En estos territorios de dominio del agronegócio buscamos comprender cómo se entrelazan la cuestión agraria, el trabajo y la determinación social del proceso salud-enfermedad. El enfoque teóricometodológico consistió en la revisión de la literatura, el trabajo de campo y la producción de entrevistas a trabajadoras y trabajadores campesinos de ambos países. Los resultados alcanzados muestran que detrás de la imagen de modernidad de las empresas del agronegócio, existe un trabajo precario y degradante, ya sea por la intensificación de la jornada laboral, bien por el uso de nuevas tecnologías, o por la combinación de ambos. Pero también hay resistencias y experiencias que demuestran las disputas y relaciones de poder que constituyen los territorios.
\end{abstract}

Palavras-Clabe: Campesinado. Agronegócio. Trabajo. Brasil. México.

\section{INTRODUÇÃO}

Desde a colonização até a contemporaneidade, os países latino-americanos sofrem um intenso processo de espoliação e pilhagem dos bens da natureza (HARVEY, 2004). Atualmente, há o comprometimento da soberania alimentar em razão da commoditização da agricultura, o domínio das empresas transnacionais sobre a produção e comércio de alimentos e a abertura dos mercados para a entrada massiva de produtos alimentícios, subsidiados pelos Estados de capitalismo avançado, a preços de dumping (MARQUES, 2008; MARTÍNEZ, 2015).

Essa situação repercute na reprodução dos camponeses que, historicamente, são produtores dos alimentos básicos que abastecem a população, mas acabam sendo subordinados à exploração capitalista, seja vendendo seus produtos para intermediários capitalistas, seja vendendo sua força de trabalho para o agronegócio. Muitos não veem outras alternativas senão o abandono do campo e a busca por trabalho nos centros urbanos, aumentando a massa das periferias urbanas, ou se veem obrigados a migrar, dentro e fora de seus países, para incorporar-se ao mercado de trabalho (BARTRA, 2011; MARTÍNEZ, 2015; SUÁREZ, 2018).

O agronegócio pode ser compreendido como o conjunto de empresas capitalistas que estão relacionadas direta ou indiretamente com a produção, beneficiamento, industrialização e comercialização dos produtos e subprodutos agropecuários, florestais ou agroextrativistas, e que são comercializados predominantemente na Bolsa de Mercadorias e Futuros (BM\&F). A expressão 
commodities é utilizada para denominar essas mercadorias que são cotadas em dólar por serem produtos destinados preferencialmente à exportação e pelos preços serem regulados pelo comportamento comercial desses produtos no exterior (CARVALHO, 2005).

Com o domínio das transnacionais no mercado agroalimentar, os países latino-americanos apenas têm a possibilidade de se inserir na economia mundial em determinados segmentos. No caso brasileiro, o país especializou-se na produção de determinadas commodities que são demandadas pelo mercado internacional. Nos anos 2000, houve um crescimento extraordinário da exportação da soja, do açúcar e do álcool, do papel e da celulose, além da carne de frango e de boi. Entre 2000 e 2015, a participação dessas commodities na pauta exportadora aumentou em 263,5\%. Perpetua (2017) relaciona esse incremento a um amplo movimento de reprimarização da pauta exportadora brasileira já que a exportação de bens manufaturados passou a ter uma participação menos significativa em comparação com os produtos básicos.

Já o México encontrou outra alternativa frente a divisão internacional do trabalho investindo no processo de industrialização. No entanto, a economia mexicana é fortemente afetada pela vizinhança com os Estados Unidos e o Tratado de Livre Comércio da América do Norte (TLCAN). Além de ser um país importador de alimentos básicos, conta com uma industrialização formada por empresas maquiladoras. Trata-se de plantas industriais localizadas nas proximidades com a fronteira dos Estados Unidos que produzem bens voltados para a exportação - principalmente produtos metálicos e máquinas - e se aproveitam das facilidades físcais, do fraco controle dos poluentes e da força de trabalho abundante e barata. As maquiladoras não geram o desenvolvimento dos demais setores da economia mexicana, pois utilizam tecnologias de última geração importadas dos países de origem das corporações multinacionais (BARTRA, 2011; LÓPEZ; LLANAS, 2010; SILVA; SALOMÃO, 2018).

Apesar de o México não ser um país em que o forte da economia é a agroexportação, como o Brasil, neste texto abordaremos a questão agrária em ambos os países, pois os camponeses e as camponesas sentem na pele as consequências da divisão internacional do trabalho e do modelo neoliberal imposto aos países latino-americanos. Para continuar existindo e resistindo são, muitas vezes, obrigados a migrar, tornando-se trabalhadores assalariados, enfrentando a precarização e a degradação do trabalho, mas também se organizando coletivamente e lutando pelos seus direitos.

No México, discutiremos as relações de trabalho em um dos maiores enclaves agroexportadores, o Valle de San Quintín, no estado de Baja California, localizado próximo à fronteira com os Estados Unidos (FIGURA 1). O Valle de San Quintín é uma área de ocupação recente, 
pois era praticamente inabitado até os anos 1970. Em 2010, já contava com cerca de sete mil hectares de produção e uma população de 90 mil habitantes, destes aproximadamente 60 mil eram trabalhadoras e trabalhadores dos campos agrícolas. Atualmente, é um dos enclaves agroexportadores mais modernos e rentáveis do México com 130 empresas nacionais, estrangeiras, mistas, grandes e pequenas. Cerca de $90 \%$ da produção de hortaliças é exportada para os Estados Unidos pelas empresas Driscoll's, Berrymex e Los Pinos (DAMIÁN; GONZÁLEZ; TORRALBA, 2017).

A população de San Quintín é formada por migrantes que se estabeleceram de forma permanente no Valle. São oriundos de vários estados mexicanos, mas predominam os oaxaqueños. Também são indígenas de diferentes culturas e falam diversas outras línguas, além do espanhol. No México, existem regiões consideradas expulsórias de camponeses (Oaxaca, Guerrero, Michoacán, Zacatecas, Guanajuato, Veracruz, Jalisco e Chihuahua) e regiões atraentes (Sinaloa, Sonora e Baja California, principalmente). As primeiras são consideradas pouco produtivas, carentes de tecnologias e onde predominam as terras comunais. As segundas são constituídas por empresas agroexportadoras, organizadas em propriedades privadas, produtoras principalmente de frutas e hortaliças para exportação. Essas empresas administram seus custos mediante a força de trabalho barata dos migrantes (SUÁREZ, 2019). 
Figura 1-Valle de San Quintín, estado de Baja Califórnia, México

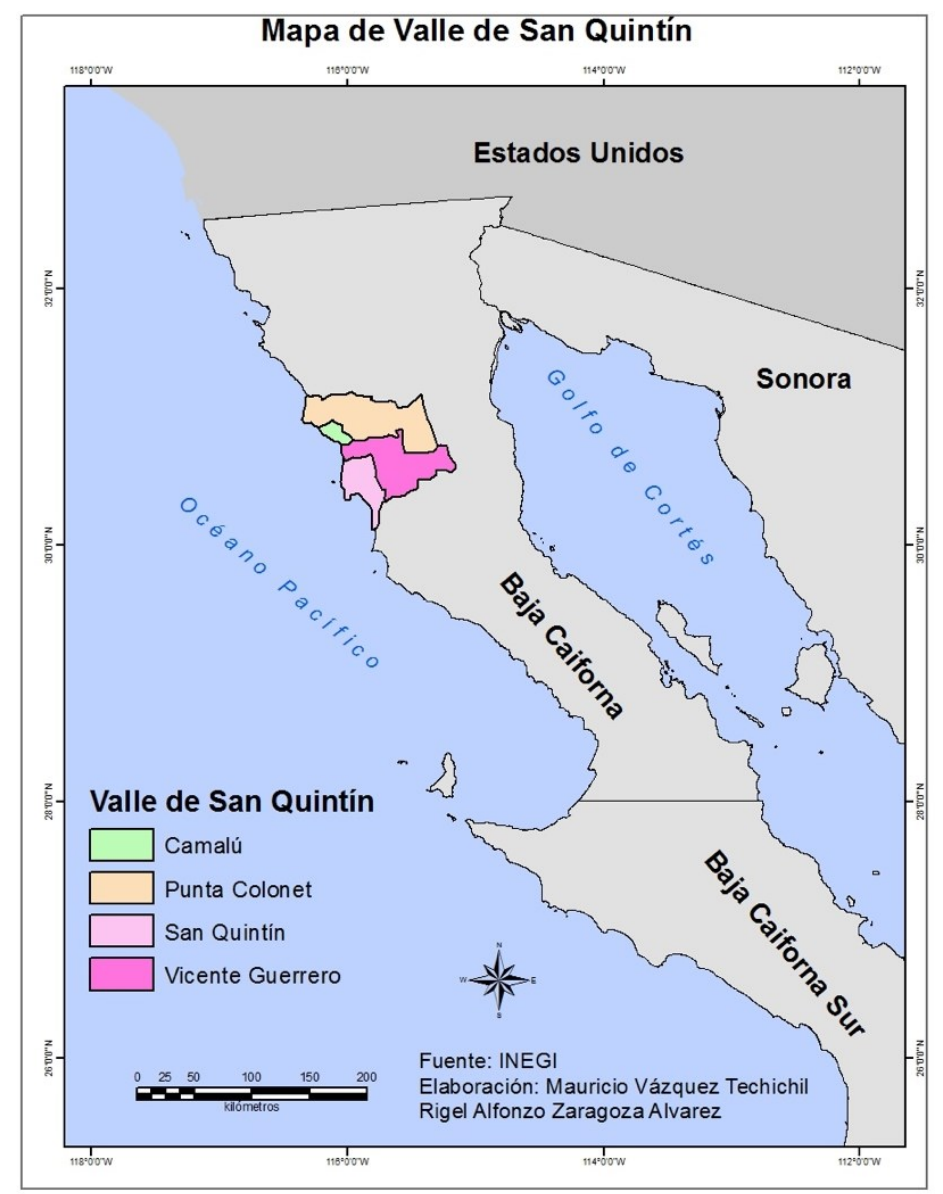

Fonte: Damián; González; Torralba (2017).

No Brasil, focaremos nas relações de trabalho do agronegócio canavieiro, no Pontal do Paranapanema, estado de São Paulo, em que existem dez unidades agroindustriais canavieiras, dentre elas três são associadas ao capital internacional: a Usina Rio Vermelho incorporada pela trading suíça Glencore (Glencane Bioenergia S/A), a Destilaria Paranapanema I adquirida pelo grupo norueguês Umoe Bioenergy e a Usina Alcídia incorporada ao grupo Odebrecht que, atualmente, mudou sua denominação para Atvos S/A (FIGURA 2). Esse cultivo teve início na região nos anos 1970 por meio 
do Programa Nacional do Álcool (PROALCOOL), mas intensificou-se nos anos 2000 também com incentivo do Estado para a produção de álcool.

Figura 2 - Pontal do Paranapanema e unidades canavieiras

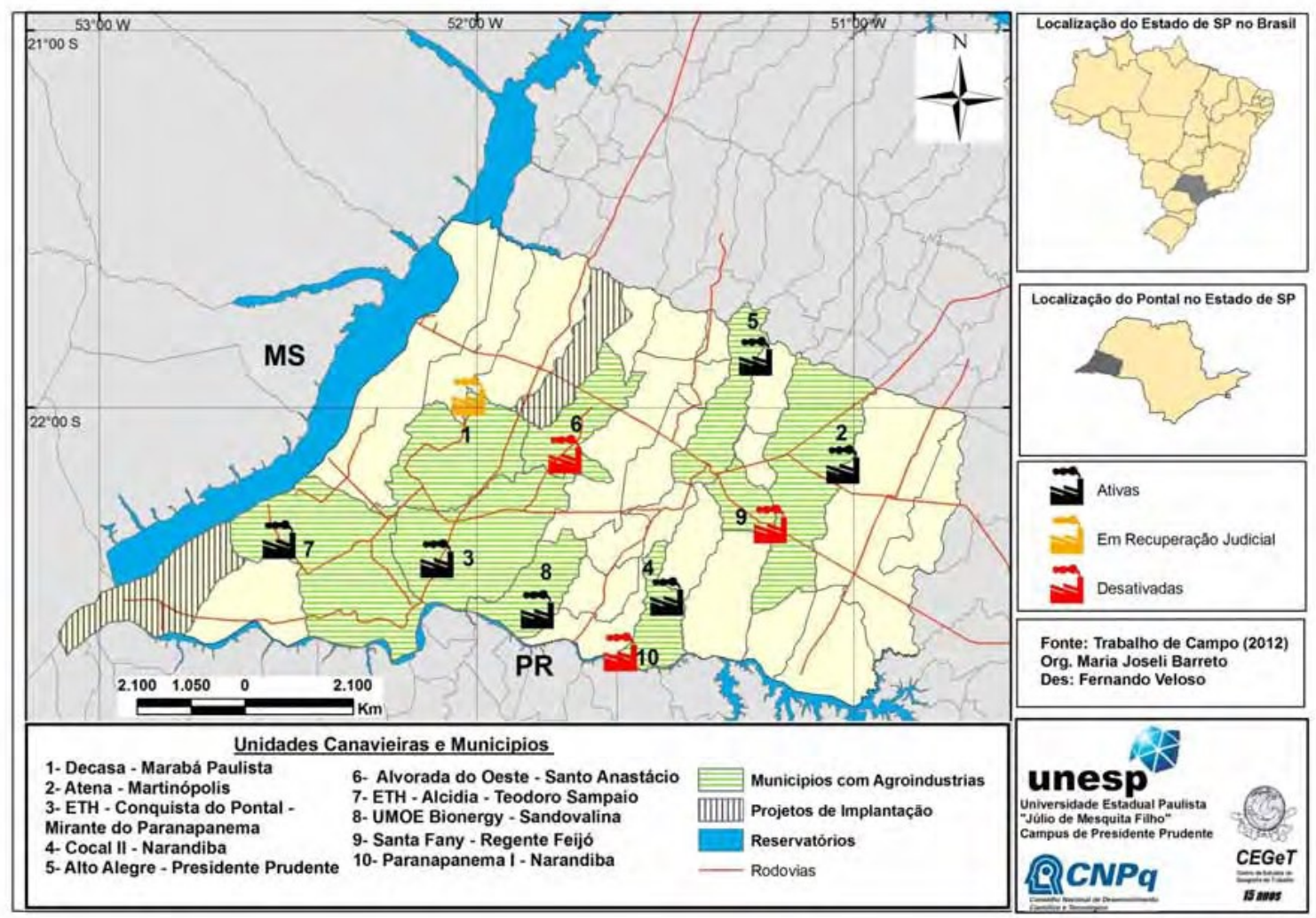

Fonte: Barreto (2012).

Por outro lado, também há mais de uma centena de assentamentos da reforma agrária conquistados pelos movimentos de luta pela terra no Pontal do Paranapanema (FERNANDES, 2005). No entanto, os assentamentos rurais ficaram praticamente “cercados” pelos canaviais e são, constantemente, atingidos pela deriva da pulverização aérea dos agrotóxicos ${ }^{1}$ que são lançados na monocultura canavieira (FIGURA 3). Essa situação gera diversos problemas para os camponeses, tanto na saúde como na produção. A contaminação por agrotóxicos somada à falta de políticas públicas para a agricultura camponesa, não deixa outra alternativa para as famílias camponesas senão buscar outras fontes de renda externas ao lote (LEAL, 2017; MACHADO, 2020).

\footnotetext{
${ }^{1}$ Isso também acontece no Valle de San Quintín em que as trabalhadoras e trabalhadores têm contato com agroquímicos na jornada laboral e nas moradias próximas ao local de trabalho.
} 
Figura 3 - Entrada do Assentamento Água Sumida, em Teodoro Sampaio, cercado pela cana-de-açúcar.

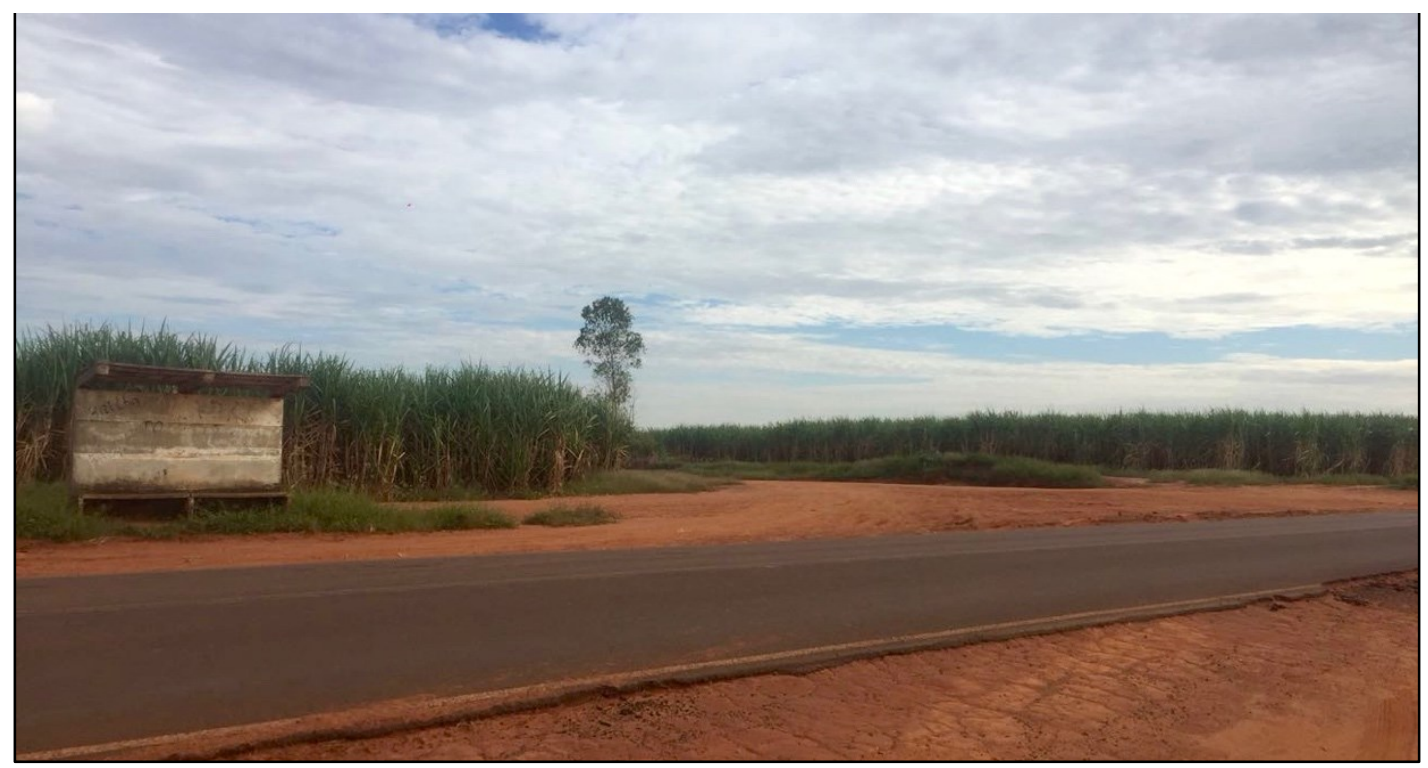

Foto: autor(a) (2018).

No agronegócio canavieiro evidencia-se a invisibilidade das reais condições de trabalho tendo em vista que o plantio e o corte de cana-de-açúcar encontram-se quase totalmente mecanizados e a imagem do cortador manual de cana, coberto de fuligem, foi substituída pelo operador de máquinas em cabines fechadas com ar-condicionado (BARRETO, 2018). No entanto, nosso objetivo é evidenciar as condições de trabalho ocultadas pela imagem da modernização.

Na produção de hortaliças e frutas, no Valle de San Quintín, predomina o trabalho manual cujas condições degradantes e precárias são evidentes. Apesar do discurso de modernidade também comparecer nas empresas instaladas na região, a modernização tecnológica é visível apenas no processo produtivo (irrigação por aspersão e gotejamento, produção em estufas, sementes modificadas, transporte refrigerado etc.), mas no que se refere as condições de trabalho são as mais deteriorantes possíveis (FIGURA 4). 
Figura 4 - Produção em estufas em San Quintín - Baja California

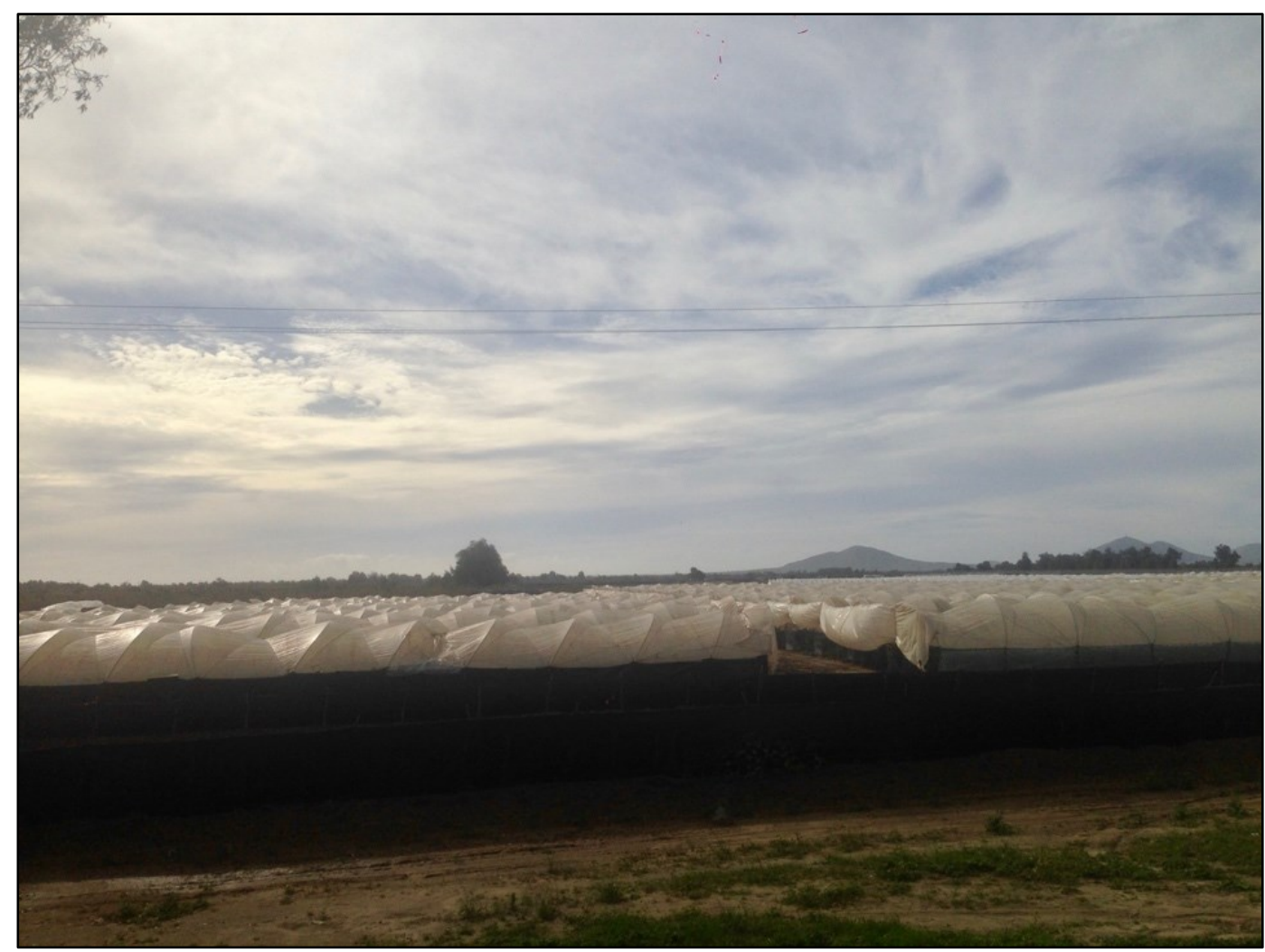

Fonte: autor(a) (2019).

Em ambos os casos, podemos compreender que o trabalho para o agronegócio se caracteriza como alternativa de sobrevivência e resistência para os camponeses diante de um quadro de políticas neoliberais que favorecem ao grande capital e relega a agricultura camponesa ao abandono.

\section{ABORDAGEM TEÓRICO METODOLÓGICA}

Este artigo é fruto da dissertação que buscou compreender os fatores que levam os assentados da reforma agrária a buscarem trabalho no agronegócio canavieiro, no Pontal do Paranapanema. A pesquisa foi associada a um amplo projeto temático que visava compreender os múltiplos impactos da expansão canavieira na região. Associada a pesquisa de mestrado, recebemos uma Bolsa de Estágio em Pesquisa no Exterior (BEPE) e tivemos a oportunidade de pensar o mundo do trabalho e do campesinato em uma escala mais ampla, no México.

$\mathrm{Na}$ Universidad Autónoma Metropolitana, cursamos disciplinas do mestrado em Desarrollo Rural em que pudemos ler e debater textos sobre a questão agrária na América Latina, 
sobretudo no México. Também realizamos trabalhos de campo para conhecer experiências da realidade agrária e de resistências camponesa e indígenas (as identidades camponesas e indígenas são fortemente associadas no México).

Neste artigo, discutimos alguns elementos observados no trabalho de campo realizado, em 2019, junto com uma pesquisadora mexicana no Valle de San Quíntin. Não conseguimos entrar nos campos de cultivo, mas conseguimos realizar entrevistas com as trabalhadoras e os trabalhadores em suas residências, para entender as condições de vida e de trabalho enfrentadas no cotidiano do Valle.

No Pontal do Paranapanema, tivemos a oportunidade de realizar diversos trabalhos de campo entre 2017 e 2019, decorrentes das atividades do projeto temático e da pesquisa de mestrado, e entrevistas com camponeses assentados que trabalham no setor canavieiro, autoridades públicas e profissionais de saúde.

Assim, utilizamos pesquisa qualitativa e produção de entrevistas semiestruturadas que nos permitiram compreender as percepções dos sujeitos sobre as relações de trabalho e o processo saúde-doença delas decorrentes (GEERTZ, 1989; COLOGNESE; MÉLO, 1998; BECKER, 1999; RIBEIRO,1999; MEYHI; 2002).

Discutimos aqui alguns aspectos que acreditamos que podem ser comparativos entre as duas realidades estudadas que, apesar de suas peculiaridades, apresentam aspectos semelhantes no que diz respeito à impossibilidade de manter-se exclusivamente do trabalho camponês e a degradação do trabalho no agronegócio.

Nesse sentido, vale a pena esclarecer nosso entendimento sobre os conceitos de campesinato, degradação e precarização do trabalho, e determinação social do processo saúde-doença. De acordo com Shanin (2005), a unidade rural familiar é o núcleo de organização econômica e social do campesinato. A terra representa mais que uma unidade de produção, mas um modo de vida que é produtor de identidade. A família camponesa produz para o autoconsumo, mesmo que de forma insuficiente e intercalando com fontes externas de renda, pois uma de suas características é a flexibilidade para encontrar novas formas de assegurar a reprodução familiar.

A degradação do trabalho está relacionada com os adoecimentos relacionados às atividades laborais enquanto a precarização tem um significado de instabilidade, fragilidade e insuficiência de direitos (SILVA, 2012). A precarização é um processo de perda de direitos conquistados pela classe trabalhadora (ALVES, 2007) e pode ser evidenciada pela flexibilização da contratação, da jornada de trabalho e da remuneração. 
Perpetua (2016, p.297) enfatiza a relação entre a precarização e a degradação do trabalho, esta última compreendida como "o processo que afeta negativamente a saúde e o bem-estar físico e mental do trabalhador decorrente, direta ou indiretamente, da atividade laboral na qual esse se encontra inserido". A degradação do trabalho está relacionada com as formas de organização e controle do trabalho que afetam diretamente a saúde das trabalhadoras e dos trabalhadores.

Portanto, verifica-se a necessidade de uma articulação teórica entre a saúde e a sociedade viabilizada pela teoria da determinação social do processo saúde-doença que tem como eixo central o trabalho como estruturador da vida social (MENDES; DIAS, 1991). A relação entre o processo social e o processo saúde-doença evidencia-se pelo modo como cada grupo social se insere no sistema produtivo e se relaciona com outros grupos sociais. O caráter social do adoecimento não pode ser evidenciado em casos individuais, mas nas formas como grupos humanos adoecem e morrem (LAURELL, 1982).

\section{O TRABALHO NOS TERRITÓRIOS AGROEXPORTADORES: CANA-DE-AÇÚCAR NO BRASIL E HORTIFRUTI NO MÉXICO}

De acordo com Raffestin (1993), o território é um espaço apropriado, de forma concreta ou abstrata, e determinado por relações sociais. Ele também é uma totalidade que contempla múltiplas dimensões (econômica, política, social, cultural e ambiental) que interagem com outros territórios em múltiplas escalas (FERNANDES, 2008).

Assim, a formação de um enclave agroexportador no México e uma área de expansão da cana-de-açúcar no Brasil podem ser compreendidos por meio das relações de poder em que grupos econômicos se apropriam de determinados territórios para atender demandas regionais, nacionais ou internacionais e, assim, modificam e criam novas paisagens e relações sociais, mas também podem ser agentes que provocam mudanças em outros territórios, por exemplo, atraindo força de trabalho de outros estados.

Os atributos físicos dos territórios também são elementos atrativos para os capitalistas. Em ambos os casos pode-se observar a importância da renda diferencial I, no caso de San Quintín em razão de sua localização privilegiada - próxima da fronteira com os Estados Unidos, maior centro consumidor da produção do Valle, que denota uma vantagem referente ao transporte de mercadorias. E no caso do Pontal do Paranapanema, podemos apontar o acesso abundante à água e um relevo que propicia a mecanização da agricultura. 
As relações de poder são constituintes dos territórios e de todas as relações sociais, assim por mais que as grandes empresas capitalistas exerçam seu domínio econômico nos territórios, os outros sujeitos que ali vivem disputam as diversas dimensões do território (material e imaterialmente). No Pontal do Paranapanema, existem mais de uma centena de assentamentos da reforma agrária e experiências agroecológicas e de comercialização da produção camponesa que buscam relações mais sustentáveis para o território (FIGURA 5). No Valle de San Quintín, as trabalhadoras e trabalhadores se organizaram em sindicatos e movimentos sociais para reivindicar direitos e proteger suas identidades culturais.

Figura 5 - Produção de alimentos agroecológicos no Assentamento Rodeio - Presidente Epitácio

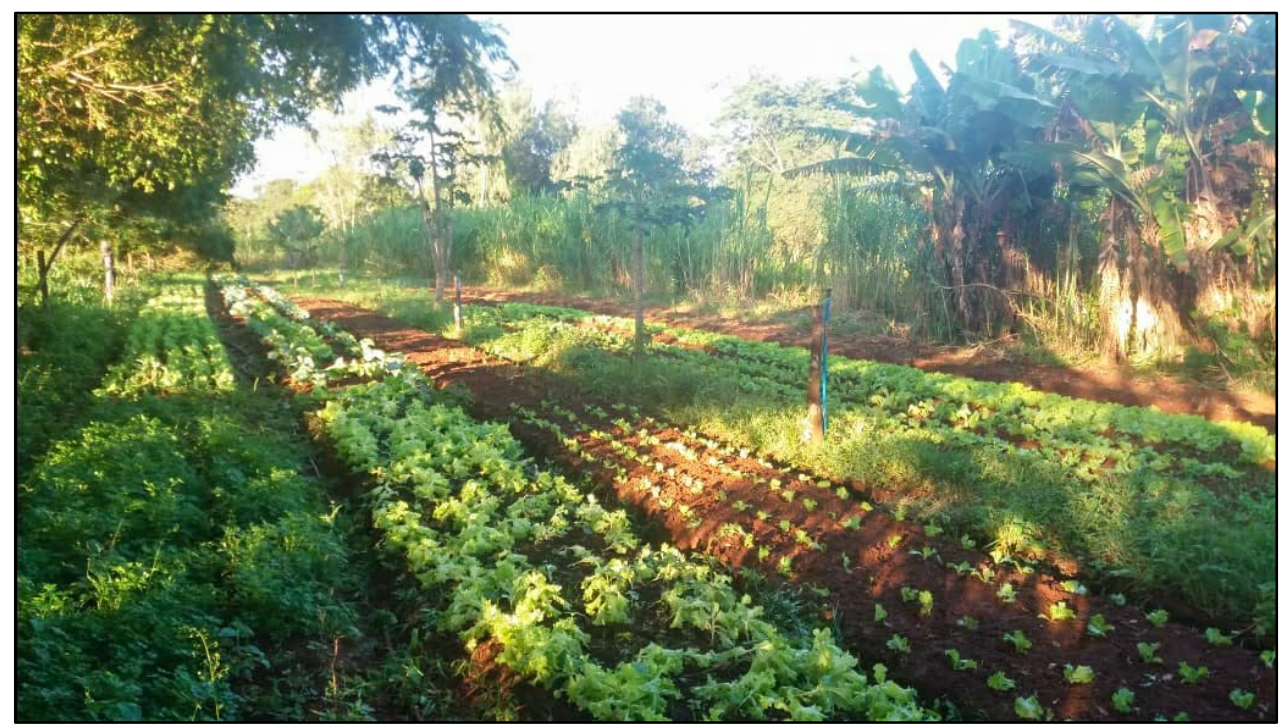

Foto: Movimento dos Trabalhadores Rurais Sem Terra. Setor de Comunicação - Agroecologia no Pontal (2020).

A denominação "territórios agroexportadores" do título desta seção faz referência ao domínio das grandes empresas, mas não exclui a existência de outras forças que dão vida aos territórios. Portanto, é nessa trama de relações sociais e de poder, constituintes dos territórios, que buscamos compreender como se entrelaçam a questão agrária, o trabalho e a determinação social do processo saúde doença nas áreas de estudo.

Os camponeses de ambos os países trabalham para o agronegócio por não terem condições de se sustentarem somente da agricultura e isso está relacionado com as formas como esses camponeses são atingidos pela divisão internacional do trabalho e as políticas neoliberais. As empresas buscam afirmar-se sob uma imagem de modernidade, mas as relações de trabalho evidenciam que as novas tecnologias não têm beneficiado as trabalhadoras e os trabalhadores. Em 
ambas as áreas de estudo há queixas sobre a exposição aos agroquímicos, as intensas jornadas laborais e as formas de controle do trabalho.

No Pontal do Paranapanema, a opção mais viável de trabalho, segundo os assentados entrevistados, é no agronegócio canavieiro que atualmente se encontra quase totalmente mecanizado. Entrevistamos dois ex-cortadores manuais de cana-de-açúcar (um homem e uma mulher), quatro operadores de colhedeira (um que já não atua mais na função), dois tratoristas agrícola (um trabalha no plantio e o outro no reboque) e um motorista de caminhão que transporta matéria-prima. Todos moradores de assentamentos da reforma agrária.

A força de trabalho no Valle de San Quintín é constituída por camponeses pobres imigrantes de outros estados do México e que foram atraídos para ali justamente para trabalhar na produção de hortifrúti para grandes empresas nacionais e transnacionais.

Podemos apontar algumas diferenças entre o Pontal do Paranapanema e o Valle de San Quintín: no primeiro, predomina o trabalho mecanizado e, no segundo, o trabalho manual. No Pontal, as camponesas e camponeses foram atraídos pela reforma agrária e pela possibilidade de viver da agricultura camponesa, mas em razão de diversas dificuldades, muitos têm que trabalhar para o agronegócio. No Valle, a força de trabalho é totalmente imigrante e o que a atraiu foi justamente a oportunidade de trabalho nas grandes empresas.

Outros aspectos de semelhanças e diferenças serão apontados no decorrer do texto. No momento vamos enfatizar as relações de trabalho. No trabalho mecanizado, existe uma diversidade de funções e, consequentemente, diferentes níveis de exposição aos riscos no ambiente de trabalho. Com a mecanização ocorre a redução das cargas físicas (exposição ao sol, à poeira, ao vento), mecânicas (movimentos rápidos e repetitivos) e químicas (agroquímicos) quando comparadas ao cortador de cana-manual, por exemplo. Mas, essa redução não significa a inexistência dessas cargas.

Os tratoristas que lidam com os tratos culturais ainda têm contato direto com os agroquímicos e, mesmo os que exercem outras funções, relataram que os aviões que pulverizam agrotóxicos, muitas vezes, passam por cima de onde eles estão trabalhando. Além disso, a redução das cargas físicas e químicas dependem das condições das máquinas, pois há relatos de equipamentos que não funcionam nas condições ideais (fechadas e com ar-condicionado).

Em ambas as áreas de estudo, as trabalhadoras e os trabalhadores estão expostos aos agroquímicos até mesmo em suas residências, em razão da proximidade com as áreas de cultivo. No Pontal do Paranapanema, a contaminação advém das denominadas "derivas” da pulverização aérea, 
e, em San Quintín, porque algumas das comunidades onde vivem a classe trabalhadora são vizinhas das estufas produtivas (FIGURA 6).

Figura 6 - Comunidade vizinha às estufas da empresa Los Pinos

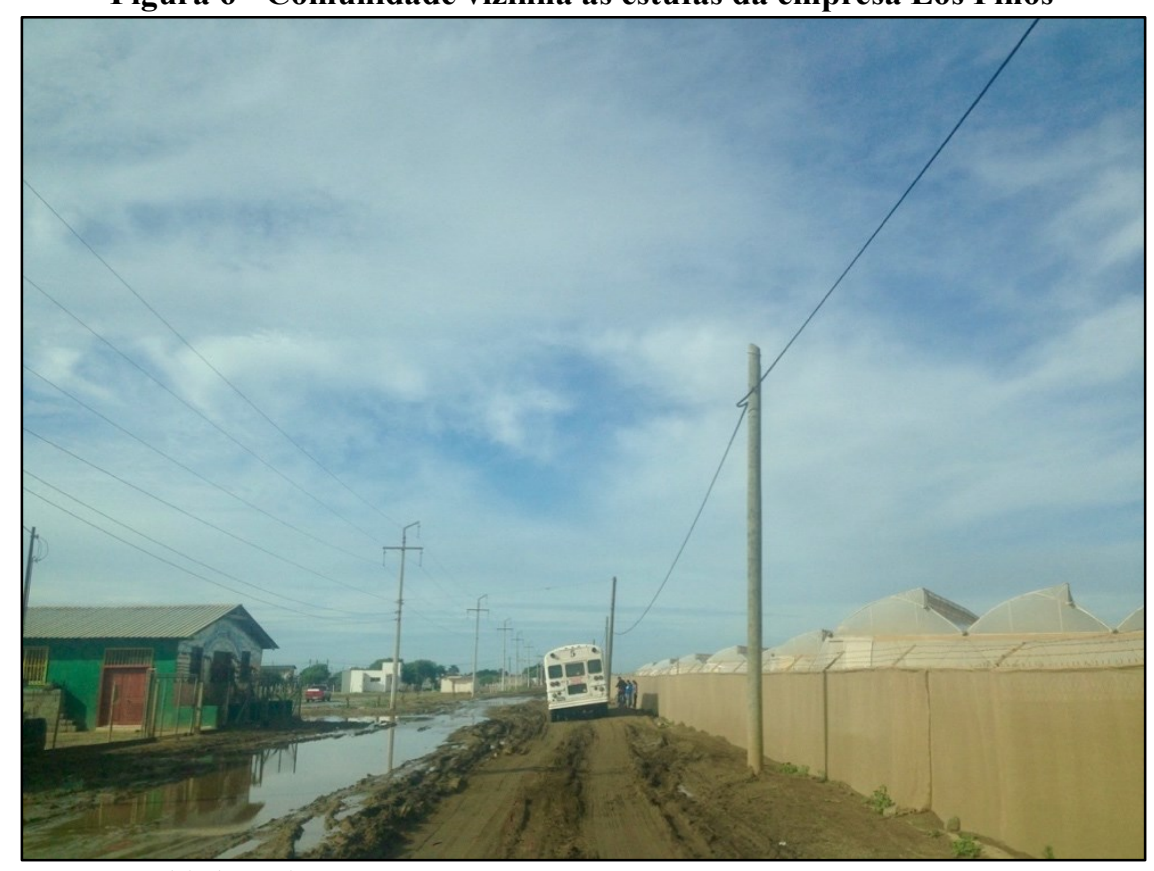

Foto: autor(a) (2019).

Nas comunidades vizinhas às estufas há relatos de casos de aborto, pessoas adoecidas com diferentes tipos de câncer e casos de má formação congênita. Infelizmente, entre 1980 a 1990, o estado de Baja California esteve em primeiro lugar nacional em casos de defeito do tubo neural (DAMIÁN; GONZÁLEZ; TORRALBA, 2017).

No Pontal, também existem indícios de relação entre os agroquímicos e problemas alérgicos, auditivos, intoxicação, má formação congênita, câncer nos animais de criação, diminuição de abelhas e de peixes nos rios. O município de Sandovalina, com menos de quatro mil habitantes, também carrega uma infeliz colocação no ranking de crianças nascidas com má formação congênita: o segundo município do estado de São Paulo ${ }^{2}$. A secretaria de saúde do município, em entrevista, confirmou que o aumento dos casos de câncer e de doenças respiratórias coincide com a expansão da cana-de-açúcar.

Com relação ao perfil das trabalhadoras e dos trabalhadores, evidencia-se que o trabalho nos canaviais do Pontal do Paranapanema é predominantemente masculino. Apesar de existirem

\footnotetext{
${ }^{2}$ Outras palavras. Maldição em Sandovalina. Disponível em: < https://outraspalavras.net/blog/2017/08/31/maldicaoem-sandovalina/>. Acesso em 21 mai 2018.
} 
mulheres que trabalham no corte e plantio de cana-de-açúcar mecanizados, de acordo com os relatos dos trabalhadores, elas são minoria. Barreto (2018) enfatiza que elas estão entre os descartados pela reestruturação produtiva, juntamente com o conjunto de pessoas que: estão em idade avançada; têm baixos níveis de escolaridade; estão adoecidas pelo trabalho no corte manual da cana-de-açúcar; ou são migrantes sazonais. $\mathrm{O}$ trabalho feminino na cana-de-açúcar predomina nas atividades manuais, mais degradantes e precárias, tais como a "bituca" recolhendo os pedaços de cana-de-açúcar deixados pela máquina, os tratos culturais (carpa química e controle de pragas) e sem registro em carteira de trabalho (trabalhadoras avulsas).

As mulheres trabalhadoras do Valle de San Quintín, além de enfrentarem a precarização e a degradação do trabalho, são duplamente exploradas em razão da rotina de trabalho doméstico que recai sobre elas, madrugando para preparar a comida e arrumar a casa e os filhos antes de ir ao trabalho nos campos. Quando retornam novamente têm mais trabalho antes de poderem descansar, para no outro dia começar tudo outra vez. Existe uma série de complicadores para as mulheres no Valle como a maternidade sem direito algum, falta de creches para os filhos, e, ainda, o assédio sexual por parte dos encarregados.

Com relação às jornadas laborais, no setor canavieiro predomina o trabalho em turnos turno A: $7 \mathrm{~h} 00$ às 15h00; turno $\mathrm{B}$ : $15 \mathrm{~h}$ às 23h00; turno $\mathrm{C}$ : $23 \mathrm{~h} 00$ às $7 \mathrm{~h} 00$. Portanto, são 8 horas de jornada de trabalho, mas se for contabilizado o tempo de trajeto casa-trabalho-casa soma-se cerca de 4 horas, totalizando aproximadamente 12 horas em que os camponeses ficam fora do assentamento. Além disso, eles ainda realizam trabalhos na unidade rural, com destaque para as atividades relacionadas com a produção leiteira.

Em San Quintín, as trabalhadoras e os trabalhadores não têm terra disponível para produzir e vivem exclusivamente do trabalho assalariado. Trabalha-se por dia ou por produção, na maioria dos casos, sem contrato de trabalho e sem nenhum direito social e trabalhista. A jornada laboral chega a ultrapassar 12 horas de trabalho e recebem cerca de $\$ 100$ a $\$ 120$ pesos mexicanos por dia, cerca de $\mathrm{R} \$ 20,00$ a $\mathrm{R} \$ 25$ reais, que resulta em aproximadamente $\$ 3.600$ pesos por mês, $\mathrm{R} \$ 750,00$. Se a Lei Federal do Trabalho fosse cumprida, as trabalhadoras e os trabalhadores receberiam cerca de $62 \%$ a mais do que recebem, mas as empresas atuam na mais pura ilegalidade (DAMIÁN; GONZÁLEZ; TORRALBA, 2017).

No estado de São Paulo, em 2019, o salário médio do operador de colheitadeira era de $\mathrm{R} \$ 1.831,26$, o de tratorista $\mathrm{R} \$ \mathrm{R} \$ 1.554,33$, o de motorista de caminhão $\mathrm{R} \$ 1.923,56$, o de trabalhador 
volante da agricultura que realiza inúmeras atividades na função de auxiliar agrícola, recebeu o menor salário, no valor de R\$1.109,87 (MINISTÉRIO DO TRABALHO, 2020).

Em San Quintín, quando é temporada de certas frutas como o morango, as trabalhadoras e os trabalhadores preferem trabalhar por produção quando esforçam seus corpos até o limite para poder ganhar um pouco mais e economizar para os meses em que a produção está baixa. Nesse caso, a jornada laboral se estende até que se alcance a meta de colheita estabelecida pelos patrões.

Em ambos os contextos de trabalho existe uma forte pressão pela produtividade. No agronegócio canavieiro são estabelecidas metas diárias e mensais, os trabalhadores recebem uma participação de até $30 \%$ sobre o salário quando se alcança a meta. No entanto, os entrevistados afirmam que se faltarem um dia ou receberem uma advertência não recebem a bonificação, evidenciando uma forma de controle do trabalho. Relatam a dificuldade de lidar com a pressão diária pelas metas, o que causa um grande estresse, umas das principais queixas dos trabalhadores da mecanização agrícola. Quando não atingem a meta de determinado número de hectares plantados, por exemplo, mil hectares em um mês, o trabalhador vai acumulando o déficit que se soma a meta do mês seguinte, tornando a pressão ainda maior.

Assim, o trabalho acontece em ritmo intenso. Um dos trabalhadores relatou que, muitas vezes, não dava tempo de parar para almoçar de modo que realizava a refeição no ônibus quando estava no trajeto de volta para a casa ou até mesmo comia dentro do trator enquanto trabalhava. $\mathrm{O}$ ritmo frenético em que se dá o trabalho é a causa de diversos acidentes, dentre os quais destaca-se as colisões e tombamentos das máquinas. Elas podem tombar, principalmente, em razão das irregularidades dos terrenos e de buracos abertos pelos formigueiros no meio dos canaviais. Também existe o risco de colidir em árvores e postes de rede de transmissão de energia, nesse último caso também há o perigo relacionado à eletricidade.

Outro fator de risco bastante mencionado pelos entrevistados está relacionado ao incêndio das máquinas. De acordo com os relatos, é bastante comum esse tipo de situação já que as máquinas nunca param de funcionar, trabalham noite e dia, aquecendo e juntando palha seca da cana-de-açúcar. Além de contarem com detector de chamas e kit anti-incêndio, há sempre um caminhão-pipa acompanhando de perto as máquinas colhedeiras. Mesmo assim, os entrevistados relatam casos de máquinas que queimaram totalmente. Um incêndio no canavial, em 2016, foi fatal para um motorista de caminhão-pipa que também era assentado ${ }^{3}$.

\footnotetext{
${ }^{3}$ Fato relatado nas entrevistas e noticiado pela imprensa. Disponível em: http://g1.globo.com/sp/presidente-prudenteregiao/noticia/2016/10/motorista-morre-carbonizado-apos-caminhao-tombar-em-pres-epitacio.html. Acesso em 25 out. 2019.
} 
Os riscos mencionados nas entrevistas decorrentes do processo de trabalho podem ser classificados como físicos; mecânicos e de acidentes; químicos; ergonômicos; biológicos; e organizacionais (AGOSTINI, 2002). De acordo com as entrevistas, esses riscos podem ser relacionados, sobretudo, ao ritmo intenso das atividades laborais. Com relação aos riscos organizacionais, evidencia-se a jornada de trabalho longa e com o ritmo intenso; os turnos alternados e noturnos; o trabalho repetitivo e monótono; o excesso de responsabilidade; a falta de pausas; as horas-extras; a cobrança excessiva por produtividade; as relações de trabalho autoritárias; mecanismos de coerção e punição; exigência de posturas e posições desconfortáveis.

Os problemas em San Quintín extrapolam o ambiente de trabalho e se manifestam nas diversas dimensões sociais. Faltam as mais básicas infraestruturas como água encanada e unidades de saúde. A população precisa comprar água de caminhões-pipa e o atendimento médico depende de caravanas que deveriam passar a cada 15 dias pelas comunidades, mas chegam a ficar meses sem aparecer. As pessoas idosas não conseguem se aposentar já que trabalham toda a vida sem a contribuição ao Instituto Mexicano de Seguridade Social (IMSS). Muitas famílias dependem de programas de assistência social.

O trabalho é realizado em jornadas intensas onde os trabalhadores e as trabalhadoras são submetidos a altas temperaturas dentro de estufas com pouca ventilação, não recebem pagamento de horas extras, não tem contrato de trabalho, nem descanso semanal, nem férias, nem acesso à seguridade social, nem $13^{\circ}$ salário.

Em 2015, as trabalhadoras e os trabalhadores de San Quintín fizeram uma grande greve para lutar por seus direitos laborais, de moradia, de alimentação e de saúde, além de exigirem o fim do trabalho infantil (ainda uma triste realidade) e do assédio sexual, além de lutarem pela liberdade e autonomia sindicais. Uma das vitórias do movimento foi a constituição do Sindicato Independiente Nacional Democrático de Jornaleros Agrícolas (SINDJA).

A resistência também se faz presente por meio de outas organizações como a Alianza de Mujeres de Diversos Colores e a Radiodifusora Cultural Indígena La Voz del Valle que além de divulgar os direitos laborais visa ajudar na difusão das culturas indígenas. A maioria das trabalhadoras e dos trabalhadores sentem-se pertencentes a suas comunidades de origem, mesmo que vivam em San Quintín a dezenas de anos e mesmo os jovens que nasceram ali. Existem feiras que comercializam os produtos típicos oaxaqueños e, apesar das dificuldades de ensinar as línguas originarias para as novas gerações, essas línguas e os costumes indígenas estão presentes no cotidiano das trabalhadoras e dos trabalhadores do Valle de San Quintín. 
No Pontal do Paranapanema, como já mencionamos, há diversos exemplos de resistência nos assentamentos. Rabello (2018) ressalta uma série de iniciativas voltadas para a produção agroecológica de alimentos, com destaque para o Projeto Café com Floresta e o Projeto Macaúba. Ambos são formados por sistemas agroflorestais (SAFs) em que se planta o cultivo principal consorciado com árvores frutíferas e nativas, além de alimentos, tais como, feijão, milho e mandioca.

Além dos SAFs, existe uma diversidade de ações voltadas para as práticas agroecológicas, tais como cursos, encontros, seminários, eventos políticos e acadêmicos, além da formação da Rede Pontal Agroecológico composta por movimentos sociais, instituições públicas, associações e cooperativas. Vale ressaltar também a formação do Centro de Referência em Agroecologia do Pontal do Paranapanema (CRAPP) e os projetos de cestas agroecológicas que comercializa os alimentos produzidos nos assentamentos nas cidades da região (RABELLO, 2018).

Portanto, evidenciamos que a opção política pelo desenvolvimento da agricultura por meio de grandes conglomerados empresariais, nacionais e transnacionais, coloca as famílias camponesas em situação de vulnerabilidade em diversos aspectos da vida, pois são obrigadas a vender sua força de trabalho ao agronegócio, enfrentando diárias laborais precárias e degradantes.

Os exemplos de resistências aqui evidenciados demonstram o potencial da agricultura camponesa de produzir alimentos saudáveis a partir de relações de trabalho que sejam para a emancipação e não para a exploração da classe trabalhadora. Para uma mudança efetiva dessa situação, seriam necessárias políticas públicas para a agricultura camponesa que a reconhecessem como produtora de alimentos, de modo que as famílias não precisem se submeter a esse tipo de trabalho para sobreviverem.

\section{CONSIDERAÇÕES FINAIS}

Nesse artigo tivemos o objetivo de discutir a questão agrária, o trabalho e o processo saúde-doença que permeiam a vida das camponesas e dos camponeses brasileiros e mexicanos. Diante do desenvolvimento do sistema capitalista de produção, o campesinato necessita reinventar-se a todo instante para continuar existindo e resistindo. Infelizmente, algumas vezes não há outra alternativa senão vender sua força de trabalho ao grande capital agroexportador.

Nos campos considerados mais modernos, o trabalho é precário e degradante, seja pela extração da mais-valia absoluta (intensificação da jornada de trabalho), seja pela mais-valia relativa 
(uso de novas tecnologias), ou pela combinação de ambas, o capital lucra sobre as vidas das trabalhadoras e dos trabalhadores, sem se importar com os seres humanos que exercem o trabalho.

Felizmente, as resistências existem e persistem na luta pela efetivação de direitos sociais, trabalhistas e pela construção de um novo mundo possível. Apesar dos grandes desafios enfrentados pelas trabalhadoras e pelos trabalhadores, também é grande a consciência de que necessitam organizar-se para mudar a situação em que vivem.

\section{AGRADECIMENTOS}

Agradecemos a Fundação de Amparo à Pesquisa do Estado de São Paulo (FAPESP).

\section{REFERÊNCIAS BIBLIOGRÁFICAS}

AGOSTINI, M. Saúde do trabalhador. In: ANDRADE, A.; PINTO, S. C.; OLIVEIRA, R. S. Animais de laboratório: criação e experimentação [on line]. Rio de Janeiro: Editora Fiocruz, 2002.

ALVES, G. Dimensões da reestruturação produtiva: ensaios de sociologia do trabalho. Londrina: Práxis/Bauru: Canal 6, 2007.

BARRETO, M.J. Territorialização das agroindústrias canavieiras no Pontal do Paranapanema e os desdobramentos para o trabalho. 245 f. Dissertação (Mestrado em Geografia). Universidade Estadual Paulista Júlio de Mesquita Filho, Presidente Prudente, 2012.

BARRETO, M.J. Novas e velhas formas de degradação do trabalho no agrohidronegócio canavieiro nas regiões administrativas de Presidente Prudente e Ribeirão Preto (SP). 377 f. Tese (Doutorado em Geografia). Universidade Estadual Paulista Júlio de Mesquita Filho, Presidente Prudente, 2018.

BARTRA, A. Os novos camponeses: leituras a partir do México profundo. São Paulo: Cultura Acadêmica; Cátedra Unesco de Educação do campo e Desenvolvimento Rural, 2011.

BECKER, H. S. Métodos de pesquisa em ciências sociais. São Paulo: HUCITEC, 1999.

CARVAlHO, H. M. de. O campesinato no século XXI: possibilidades e condicionantes do desenvolvimento do campesinato no Brasil. Rio de Janeiro: Vozes, 2005.

COLOGNESE, S. A.; MÉLO, J. L. B. de. A técnica de entrevista na pesquisa social. Cadernos de Sociologia, Porto Alegre, v. 9, p. 143 - 159, 1998.

CONCHEIRO, L.; ROBLES, H. Tierra, territorio y poder a cien años de la reforma agraria en México. Lucha y resistencia campesina frente al capital. In. ALMEYRA, G. et al. Capitalismo, tierra y poder en América Latina (1982-2012). Universidad Autónoma Metropolitana - Xochimilco, Cidade do México, 2014. 
DAMIÁN, G.E.; GONZÁLEZ, E.R.; TORRALBA, A.T. Vivir para el surco: trabajo y derechos en el Valle de San Quintín. Universidad Autónoma Metropolitana - Xochimilco, Cidade do México, 2017.

FERNANDES, B.M. Movimentos socioterritoriais e movimentos socioespaciais: contribuição teórica para uma leitura geográfica dos movimentos sociais. NERA, Presidente Prudente, ano 8, n.6, 2005.

FERNANDES, B.M. Entrando no território dos territórios. In: PAULINO, E. T.; FABRINI, J. E. (Orgs.). Campesinato e território em disputa. 1 ed. São Paulo: Expressão Popular, 2008, p. 273302.

GEERTZ, C. Estar lá, escrever aqui. Diálogos, São Paulo, v. 22, n. 3, p. 58 - 63,1989.

GIBBS, G. Análise de dados qualitativos. Porto Alegre: ArtMed, 2009.

HARVEY, D. O novo imperialismo. São Paulo: Loyola, 2004.

LAURELL, A.C. La Salud-Enfermedad como processo social. Cuadernos Médico Sociales. N. 19, p.01-11, jan., 1982.

LEAL, S.C.T. A dinâmica territorial do Programa de Aquisição de Alimentos (PAA), no Pontal do Paranapanema-SP no contexto dos conflitos. Dissertação (mestrado em Geografia). Universidade Estadual Paulista "Júlio de Mesquita Filho", Presidente Prudente, 2017.

LÓPEZ, R.V.; LLANAS, C.P. Nueva división internacional del trabajo y cambio en la estructura industrial de la economia mexicana. In: BERNAL, C.A.R.; TOTO, R.M.C. La quimera del desarrollo mexicano. Cidade do México: Universidad Autónoma Metropolitana, Xochimilco, 2010.

MACHADO, A. dos S. A reestruturação produtiva canavieira e as implicações para a saúde dos trabalhadores assentados no Pontal do Paranapanema (SP). Dissertação (mestrado em Geografia). Universidade Estadual Paulista "Júlio de Mesquita Filho", Presidente Prudente, 2020.

MARQUES, M. I. M. Agricultura e Campesinato no Mundo e no Brasil: um renovado desafio à reflexão teórica. In: PAULINO, E. T.; FABRINI, J. E. (Org.). Campesinato e Territórios em Disputa. 1.ed. São Paulo: Expressão Popular: UNESP. Programa de Pós-Graduação em geografia, 2008.

MARTÍNEZ, M.E. La lucha por la tierra en el siglo XXI. La actualidad de la cuestión agraria en México y Brasil. Dissertação (Mestrado em Estudos Latino-americanos). Universidad Nacional Autónoma de México, 2015.

MEIHY, J. C. S. B. Manual de história oral. São Paulo: Loyola, 2002.

MENDES, R.; DIAS, E.C. Da medicina do trabalho à saúde do trabalhador. Saúde Pública, São Paulo, v.25, n.5, p.341-9, 1991.

MINISTÉRIO DO TRABALHO. Classificação Brasileira de Ocupações. Disponível em: http://www.mtecbo.gov.br/cbosite/pages/pesquisas/BuscaPorTitulo.jsf;jsessionid=bHZaqxj1Yf7HFr 
lgQ13dsD5X.slave22:mte-cbo. Acesso 29 mai. 2020.

PERPETUA, G.M. Pilhagem territorial, precarização do trabalho e degradação do sujeito que trabalha: a territorialização do capital arbóreo-celulósico no Brasil contemporâneo. $370 \mathrm{f}$. Tese (Doutorado em Geografia). Universidade Estadual Paulista Júlio de Mesquita Filho, Presidente Prudente, 2016.

PERPETUA, G.M. A atualidade da obra de Ruy Mauro Marini para entender o agrohidronegócio brasileiro e suas implicações para a segurança e a saúde dos trabalhadores. Sapiência: Sociedade, Saberes e Práticas Educacionais, v.6, n.2, ago.-dez., 2017.

RABELLO, D. Camponeses assentados e as práticas agroecológicas no contexto do agrohidronegócio canavieiro no Pontal do Paranapanema (SP). Dissertação (Mestrado em Geografia). Universidade Estadual Paulista Júlio de Mesquita Filho, Presidente Prudente, 2018.

RAFFESTIN, C. Por uma geografia do poder. São Paulo: Ática, 1993.

RIBEIRO, R. J. Não há pior inimigo do conhecimento que a terra firme. Tempo Social, São Paulo, 11 (1), p. 189 - 195, maio de 1999.

SHANIN, T. A definição de Camponês: conceituações e desconceituações - o velho e o novo em uma discussão marxista. Revista Nera, ano 08, no 07, Julho/Dezembro de 2005.

SILVA, E. S. A precarização contemporânea: a saúde mental no trabalho precarizado. In. ALVES, G.; VIZZACCARO-AMARAL, A.L.; MOTA, D.P. Trabalho e estranhamento: saúde e precarização do homem-que-trabalha. São Paulo: LTr, 2012.

SILVA, E.G.; SALOMÃO, I.C. Da substituição das importações à promoção das exportações: notas sobre a industrialização mexicana. FAE, vol.21, n.2, Curitiba, 2018.

SUÁREZ, M.N.S. Mercado de fuerza de trabajo rural en México. Pegada, vol.19, n.1, 2018.

SUÁREZ, M. N. S. Trabajo jornalero agrícola. Una aproximación teórica. Idónea Comunicación de Resultados, Departamento de Ciencia Económicas, Universidad Autónoma Metropolitana Xochimilco, 2019. 